\title{
Application of Fresco Art in Modern Interior Design
}

\author{
Hua Qin \\ Shengda Trade Economics\& Management College \\ Zhengzhou, China, 451191
}

\begin{abstract}
As a decorative culture, spiritual symbol and fashionable element, the wall painting art entered people's living space and has grown in popularity ever since, with its value and practical significance beyond doubt. Proceeding from "the dialectical relationship that wall painting art contains in modern interior design", this paper has illustrated that the contemporary interior wall painting is an independent industry emerging against the background of nowadays society's broad environment, namely, it's a wall painting art which follows the general trend of interior design development to achieve the coordinated design of space and subject.
\end{abstract}

Keywords-wall painting art; interior design; dialectical relationship

\section{INTRODUCTION}

In the modern society with rapid economic growth and fierce competition, people have been constantly changing their life concepts and holding increasingly higher requirements for the interior design, resulting in the interior design showing the tendency of diversified, green, culture-stressed and life-oriented development. Correspondingly, a variety of decorative styles have risen in response to the proper time and conditions, so have the techniques of expression of different decorations. With its unique artistic expression form to be involved in interior design, the wall painting art has been promoting the "interactive" relationship between human and interior space so as to meet the people's aesthetic and spiritual demands.

\section{SPACE DESIGN - DiALECTICAL RELATIONSHIP BETWEEN INTERIOR ENVIRONMENT AND WALL PAINTING ART}

The wall painting art and interior environment naturally attach to each other. On the one hand, the existence of wall painting art endows the given space with unique personality, culture and artistic sense, namely, the space construction in interior design under the guide of wall painting art enables the original spatial form sublimated and improved. On the other hand, the wall painting art design must conform to the given interior space environment since the style and functionality of interior space environment determine the content, form and color of wall painting, namely, the artistic conveyance of wall painting in the given space atmosphere.

\section{A. Space construction under the guide of wall painting art}

\section{1) Return of traditional culture}

Chinese traditional culture was formed and developed in the ancient society of China with relatively stable culture type, which are the crystallization of Chinese wisdom and the presentation of Chinese historical heritage in real life. It is precisely because of these characteristics of Chinese traditional culture make its impact on home design inevitable.

In interior design, the reflection of the traditional culture is one of the footholds of the wall painting art, and definitely the most important one. Different nationalities, regions and eras have different culture reflection. Wall painting art is a decoration method, such as the theme "The wise enjoy the waters, the benevolent enjoy the mountains" which has been always pursued by Chinese people. The application of Chinese ancient wall painting themed by landscape in interior design shall be regarded as the release and sublimation of Chinese traditional culture concepts. Moreover, with the humanism-containing feature impossible to be reproduced, the wall painting art possesses the unique imprint in its deep consciousness.

\section{2) Humanistic space creation}

As a unique graphic art, the modern interior wall painting mainly plays a role in the decoration of humanistic space in nowadays. A good wall painting shall be able to concentratedly reflect the human living environment with profound cultural connotation and the individual artistic ideas of designers. The wall painting is a form of visual expression in formative arts, and unlike the common paintings which can be moved, there are higher requirements for its artistic presentation. Meanwhile, to stand the scrutiny and test of changing times, it shall also possess artistic perspectiveness. There not only shall be new ideas about the form of artistic expression but also shall be unique consideration in the choice of materials and its anaphoric relation with environment, which requires the artists to pay attention to the new scientific materials as well as local customs and practices and to be particular about the overall coordination of specific space relation. The development of wall painting in future will be an incentive and attack on new concepts of human culture. Since the wall painting art is consumption of spiritual products, it greatly depends on the support of economic development. However, in terms of the trends of its development, the wall painting will be more changeable and liberal in the form of artistic expression, with more strong artistic expression charisma in individual character, which will become the window of humanistic soul in the optimization of human settlement.

\section{B. Individualized space creation}

From the original record of life to advanced "artistic life", the wall painting has magnified the public art, extending people's pursuit for beauty and wisdom into life space. It breaks through the defined boundary of plane painting, 
forming three-dimensional artworks, which not only beautifies the individualized space but also expands the space by the tactful use of artistic enchantment.

The wall painting shall be always consistent with the overall design style of the interior environment as well as the manifestation of human artistic individuality, which is the higher requirement presented to the interior wall painting art in new era. During the interior environment design, it's required not only to nicely adjust the relationship between wall painting and interior space, grasp the style of overall interior design and perfectly combine the wall painting pattern, color and texture with its functions, but also to perform the comprehensive study on different space atmosphere, more importantly reflect the owner's inner appeal and interest and finally, based on integrated factors (including human emotion, natural science, social information, aesthetic taste, etc.), create an interior environment which not only possesses unique artistic style but also is able to demonstrate the artistic individuality. For instance, you can draw some pictures of cartoon characters or animals in children's room. In the corner of wall, draw some pictures themed by flowers and trees, moreover, to highlight the individuality, you can draw a wall painting with sense of perspective on the wall surface inside the room, which can not only give people a refreshing feeling but also expand the space.

\section{The art communication in specific space atmosphere}

The indoor environment, as the carrier of wall painting, has close relationship with the wall painting. Although the wall painting art is a free artistic behavior, the wall painting in a particular space should follow the design principle of the unified entirety. The wall painting in the different space atmosphere will have different ways to convey the art.

- The harmony between wall painting art and interior decoration style. When human society transits from the industrial society to the post-industrial society and the information society, people have not been satisfied with the similar form of indoor design. With the parallel development of the multiculture, the different styles of interior design have also emerged. This is not only a reflection of social and historical development and cultural development, but also is the people's further demand in interior design to lay emphasis on aesthetic requirements and life styles. "The indoor design style belongs to the category of mental function in the indoor environment, and is performed with a certain art form. Its language often has a close relationship with the style of architecture and household, or is affected by the style which is shown by the literature, painting, music and other arts of the corresponding period."

- The development trend of the interior design in our country also has become more diversified under the influence of the times, thus the wall painting art derived from the building industry and the decoration industry has a higher request that the art of wall painting should be in unity and harmony with the interior decoration style. The styles of the modern interior design include traditional style, modern style, post-modern style, naturalistic style and mixed style. And while the wall painting art is integrated into space, it also has a unique artistic feature and style characteristics. The wall painting art has different forms to convey art, such as pastoral color, Chinese style, animated cartoon, and so on. So the different interior design style should choose the corresponding wall painting art. The pattern color of Europe-style wall painting is relatively neutral and low-key, and the wall painting design mainly comes from the European classical decorative symbols which are used to coordinate with European-style furniture, wall line, etc. The postmodern simple design style is rather extreme on the color of wall painting, between the two ends of black ash and super bright colors, and many of the corresponding patterns of the wall painting are the relatively abstract processed patterns.

- The uniformity of wall painting art and indoor environmental function. The wall painting art should be first unified with the indoor environmental function. Arnheim said: "If the situation of a certain space is consistent with the positive mental set of people who enter into the space, it will make people produce positive emotional reactions, so people will feel that it is accessible and enjoyable; if not consistent with or out of tune with this mind-set, it will cause people to produce negative emotional reactions, thus people will feel unpleasant or depressing." The wall painting art is ultimately to bring people visual effect of beauty. In the design composition of the wall painting art, it always considers the needs of people, in essence, that is, establishing the dominant position of people in the indoor design. The wall painting art, in indoor environment of different functions, offers people different artistic forms to convey art, which can meet people's different visual requirements.

- Most of the time of people's life is to be spent in a specific indoor environment. Under the living environment, the mass psychology forms specific ideas. Some environment requires some substance enrichment, and some environment requires some spiritual ballast. Therefore, the designer must go through the process to confirm the interior space feeling before painting the wall, which means considering people's feelings from the angle of indoor environmental function, combining people's thoughts with the indoor environmental function, bringing the recipient's emotions or feelings into the designing idea, on the contrary, it will inevitably cause viewers' psychological resistance.

- All in all, the indoor environment is the carrier of the wall painting art, and different functional spaces will also determine the different forms to convey the art. The wall painting art cannot be simply equated with general painting. Abandoning the bondage of frames, the wall painting art enters into our living space. In 
the specific space, the wall painting art should be harmonious with interior decoration style, achieve unity with the function of the indoor environment, and pay attention to set up the order with indoor environment and the environment user, so that the form change orderly and be simplified properly, having a sense of harmony and unity. The wall is the spatial segregation carrier, and is also the stage of artistic creation. The non-copied wall painting art provides new inspiration and choice for indoor space design, and also brings a unique visual enjoyment to the public.

\section{DESIGN SUBJECT --EMOTIONAL ASSOCIATIONS OF PEOPLE AND WALL PAINTING ART}

People are the subject of the environment design and service targets, and environmental demands of people determine the direction of environmental design. Nowadays, people's demands for their own living space show the multi-level, diversity and individuality tendency of returning to nature, returning to culture. So it is the most basic requirements of interior design to coordinate the mutual relationship of "people- space - environment", and to make them harmonious to form a unique, individual, and comfortable life space.

\section{A. Feeling. The experience of artistic conception}

The artistic conception refers to the implication and state that literary works convey with the aid of image. Zhu Chengjue of the Ming Dynasty said in the On Cun-Yutang Poetic Criticism that "writing poem should integrate the scene with the feeling, and beyond the words, which is the essence of the poem." These sentences stress the beauty of the artistic conception of the literary works. The composition of artistic conception is based on the space sights, and achieves "the integration of the scene and the feelings, the communication of the ideas and images" through the mastering and operation of the artistic conception, which is not only the basis of creation, but also the basis of appreciation.

Our traditional interior design often pursues the natural harmony and adjusts measures to local conditions. It also pays attention to the unified entirety, order and symmetry, and stresses the implicit and plain, false or true complement artistic conception. In the modern interior design, we should attach more importance to express feelings, and the exaggeration and omission of the modeling should achieve the goal of spiritual conveyance. The wall painting enters into the indoor decoration style as a new visual element, which plays a very important role to shape the overall artistic conception. A variety of different styles reflect people's attention to space artistic conception. Many of the natural scenes become the main material of interior wall painting, such as plants of tropical rain forest, the decorative pattern of wild animal fur, colorful fish of the underwater world and so on. These are the inexhaustible materials of decorative design. People call for loving nature and protecting the ecological balance, to find survival value and the hope from the nature, and to make the nature, harmony, peace and coexistent human voice got fully reflection by interior wall painting.
The beauty of wall painting is not only the show of the appearance, also allow people to participate, have dialogues with the ancient landscape, and to communicate and learn with the ancients, from which people can realize the beauty of artistic conception of the wall painting, and realize the beauty of the interior form of the wall painting. The use of all key elements of interior design is fundamentally to create artistic conception, and utilizes many symbolism techniques in the interior design. From the decorative form to the organization of indoor and outdoor space, from the colored pattern to the decoration, from decoration materials to decorative structure, they are all full of spirit, and everywhere is permeated with the beauty of artistic conception and the Chinese auspicious wish.

\section{B. Vision. The feeling of colors}

On the one hand, the application of wall painting color should meet the needs of life function. On the other hand, it can meet people's visual and emotional needs. The creation of space environment atmosphere can improve people's life realm, civilization and quality of life, reflecting the value of survival. Kandinsky stated in On the Spirit of the Art that "Generally speaking, the color is directly affecting the spirit. The color is like the keys, the eye is like a hammer, the mind seems to be the piano with stretched fully string, the artist is the hand to play the piano, and he purposefully plays all the keys for making people produce all kinds of waves and response." This is the emotional tendency that the color gives people. Different colors can make people produce different emotions and imaginations, for example, blue can make people feel calm, stable, reasonable, and refreshing; red can give people feelings of enthusiasm, danger, vitality, happiness, anger, and etc. which is the visual feelings that colors bring to people.

The wall painting evokes the visual emotion of people with unique techniques of performance, and the flexible application of colors. In the modern society with continuous development of the spiritual and material civilization, the wall painting meets people's pursuit of beauty for a long time, which makes the modern indoor space have a harmonious color atmosphere, and makes the space full of flavor, thus people can get enjoyable mood and wonderful feelings.

\section{Smell. Green environmental protection}

The fundamental purpose of interior design is to improve and enhance the quality of life of residence, so green decoration has become the mainstream decorative method. The appearance of wall painting brings many conveniences. In the past, people used traditional wallpaper which is produced by machines in a large quantity to decorate metope, and this wallpaper has single style and common pattern, and is lack of personality. Also, people have repeatedly questioned the environmental problem of pasting the wallpaper glue. The wall painting brings modern people simpler and more environmentally friendly way of decoration. The used acrylic paint, synthetic polymeric pigment, is the water-based paint invented in the $1950 \mathrm{~s}$, and is manufactured by the mixtion of the pigment powder and acrylic latex, with no formaldehyde and other toxic volatile material, no poison on human body, and with brilliant and lively color. It also has many other 
advantages, for example painting tool is simple and can be dried quickly, and is easy to clean and keep persistent, with strong plasticity, and will never become yellow. These advantages make it have extensive practical value. And the water used during the painting has no other additives. The wall painting truly achieves the people-centered green decoration approach.

\section{CONCLUSION}

Through the interpretation of the dialectical relationship that wall painting art contains in modern interior design, we clearly know that the integration of the wall painting art and the indoor space environment lies in the treatment of relationship between the wall painting art, design space and design subject. The dialectical relationship of wall painting art, indoor environment, and design space determines that, whether at the material level, or cultural level, there is a kind of mutual and essential contact. The paper mentioned the design subject - human is the ultimate service purpose of the design, and people's environmental needs determine the direction of environmental design. Only when we put people in the first place can we make the work humane. Only when in line with all kinds of people's "feelings" can we create a personalized interior wall painting work. Only when we insist on the tenet of "people-oriented", we can build an ideal modern interior environment and coordinate the relationship of "people-space -environment".

\section{ACKNOWLEDGMENT}

College project of scientific research fund provided by the founder of Shengda Trade Economics\& Management College in 2014

\section{REFERENCES}

[1] Liang Mei, The Movement of New Art [M]. Beijing: Central Compilation and Translation Press, 2000

[2] Yang Ruidan, Inspiration Decoration. Household Painting [M]. Beijing: China Light Industry Press, 2009

[3] Better Homes, Inspiration Decoration. Household Painting [M]. Beijing: China Light Industry Press, 2009

[4] Li Xu, Li Xuan, Pu Jiang, Interior Furnishings Design[M]. Anhui,: Hefei University of Technology Press, 2007

[5] Tang Mingyue, Sun Xun, Mural Basic Teaching [M]. Shenyang: Liaoning Art Publishing House, 2008 